\title{
INTERNATIONAL PERSPECTIVES \\ - Electronic Theses and Dissertations and Academia: A Preliminary Study From India
}

\author{
by J.K. Vijayakumar, T.A.V. Murthy, and M.T.M. Khan
}

Available online 12 March 2007

\section{INTRODUCTION}

Along with institutions around the world, Indian academic libraries are exploring the potential for electronic thesis repositories and their acceptability among the Indian academic and research community. This paper outlines the current state of doctoral theses collections in India, their usage, problems with access, and the academic and research community's attitude towards digital archiving and electronic publishing in Indian universities.

Access to $\mathrm{PhD}$ theses is problematic in India, especially access from other universities. Indian universities altogether hold a huge volume of doctoral theses in their custody. Although a large number of universities have multi campuses and regional campuses, most of them keep copies of $\mathrm{PhD}$ theses only in the central library. Hence, access to $\mathrm{PhD}$ theses collections becomes difficult. Access policies concerning $\mathrm{PhD}$ theses vary across universities, but most of them provide access only to members of their own institution, including their own faculty and research students. Most are not accessible to non-members of the library, which include research scholars of other universities.

Most libraries have good systems for technical processing and maintaining the $\mathrm{PhD}$ theses, and it is easy to locate them in Indian libraries. However, only very few universities provide interlibrary loan facilities or photocopying facilities for their $\mathrm{PhD}$ theses collections, so the availability of theses physically or as a copy for an outsider is not a reality in most Indian universities. The majority of supervisors, research students, and librarians rate $\mathrm{PhD}$ theses as having high importance in furthering research in the respective disciplines, and most supervisors advise their research students to consult $\mathrm{PhD}$ theses in their discipline. But most research students can consult them

\footnotetext{
J.K. Vijayakumar is Assistant Director of Library, American University of Antigua, PO Box W-1451, St. Johns, Antigua and Barbuda, West Indies (Earlier with INFLIBNET Center, India, while doing the study) <vijayakumarjk@yahoo.com,vijay@auamed.net>; T.A.V. Murthy is Ex. Director of INFLIBNET-UGC, Chief Librarian, Central Institute for English and Foreign Languages, Hyderabad-500007, India; M.T.M. Khan, is Dean of Arts Faculty, Professor and Head, Institute of Library and Information Science, Bundelkhand University, Jhansi-284128, India.
}

only in the same university; and only a few are able to consult $\mathrm{PhD}$ theses from another university. So although there are no major obstacles in accessing $\mathrm{PhD}$ theses from the same university, distance and the lack of a distribution mechanism are major obstacles in accessing $\mathrm{PhD}$ theses from other universities.

Access to information about $\mathrm{PhD}$ theses at a national level is also patchy. "University News" of the Association of Indian Universities (AIU), which is the only available current printed listing of $\mathrm{PhDs}$ awarded every month, does not cover doctorates in all Indian universities. Libraries participating in the Information and Library Network (INFLIBNET), a library networking program of the University Grants Commission (UGC), created a computerized database of $\mathrm{PhD}$ collections, and most of university libraries regularly contribute bibliographical details to the INFLIBNET Theses Database. Still a national level integrated system to locate and access PhD Theses has not been implemented properly.

In this context, there is great opportunity for greater use of electronic deposit and access to theses. While few Indian universities have started Electronic Thesis and Dissertation (ETD) projects, the majority of them have an intention to start such projects soon. The study reported here explores the attitudes of both librarians and scholars on this matter, whether there is a need for a national level agency for coordinating this work, what kind of policies should govern a national system, and what level of support would be necessary to sustain it.

In order to answer these questions, a survey of Indian university librarians, $\mathrm{PhD}$ supervisors, and $\mathrm{PhD}$ research students was conducted across India using a number of individually targeted questionnaires. $\mathrm{PhD}$ students and supervisors were selected from the participants in INFLIBNET's EResources Awareness program conducted at various universities across the country. These participants were therefore expected to be familiar with electronic information services.

Separate questionnaires were also sent to university librarians from eighty-seven randomly selected universities from all regions of India, according to the following criteria:

funded under UGC; or

connected to UGC Infonet; or

planning to be connected to UGC Infonet; or

having sufficient e-resources available. 
It was hoped that the survey would initiate discussion and ascertain attitudes concerning the introduction of electronic theses among the Indian academic and research community. Through this survey and data analysis, this paper attempts to present an accurate picture of doctoral thesis collections, usage, problems with access, and the academic and research community's attitude towards digital archiving and electronic publishing, etc., in Indian universities.

\section{FINDINGS}

\section{University Librarians}

Responses to the questionnaire were received from sixtyfive librarians out of the eighty-seven universities selected to be surveyed according to the above mentioned criteria. Of these sixty-five libraries, fifty-three ( 82 percent) reported that they have already created a computerized bibliographic database of their $\mathrm{PhD}$ theses collection, and only twelve (18 percent) have not done so as yet. This wide availability of bibliographic databases is likely to encourage a shift to full-text databases of electronic theses and dissertations (ETDs).

Fifty-six ( 86 percent) of the librarians responding indicated that they were aware of the concept of ETDs. But although this significant majority of librarians are aware of ETD initiatives, only twenty-two (34 percent) of university librarians responding indicated that they had adopted a policy to collect theses in electronic format along with the submission of print copies. It is important that the remaining forty-four libraries move soon to adopt a policy for submission of theses in e-formats, given the emerging culture of electronic information in the Indian academic sector.

However, this low rate of ETD project development may be linked to that fact that only thirty-one (48 percent) of the librarians responding supported the concept of making electronic theses available online while thirty-four ( 52 percent) of the libraries surveyed do not yet support online access. This may change in the near future, as uncertainty created by the relatively recent introduction of ETDs and the absence of national level policies and frameworks in this area reduces. Of the thirty-one libraries supporting online access, twelve (39 percent) supported access only on the Library LAN, nine (29 percent) supported the concept of access via the campus intranet, and only ten (32 percent) supported the concept of making theses available through the Internet (thus providing global access), obviously the optimum solution to remedy the current difficulties in accessing $\mathrm{PhD}$ theses in Indian universities. If we consider the total number of participants in this survey, only ten out of sixty-five (15 percent) respondents support global access to their theses collection. At the present time, in most countries, the majority of universities still restrict full-text global access to their ETD projects.

\section{Obstacles and Benefits Perceived in Relation to Creating an ETD System}

The librarians responding identified a number of obstacles to the creation of ETD systems in India (see Fig. 1). Out of sixty-five respondents, thirty-three librarians (51 percent) identified copyright issues as the main obstacle, while a further twenty-five (37 percent) identified infrastructure problems, twenty-three (35 percent) identified risks of plagiarism, and twenty (31 percent) identified lack of funding.

\section{Figure 1 \\ Obstacles in Creating ETD System (Respondents Could Select More than One Response)}
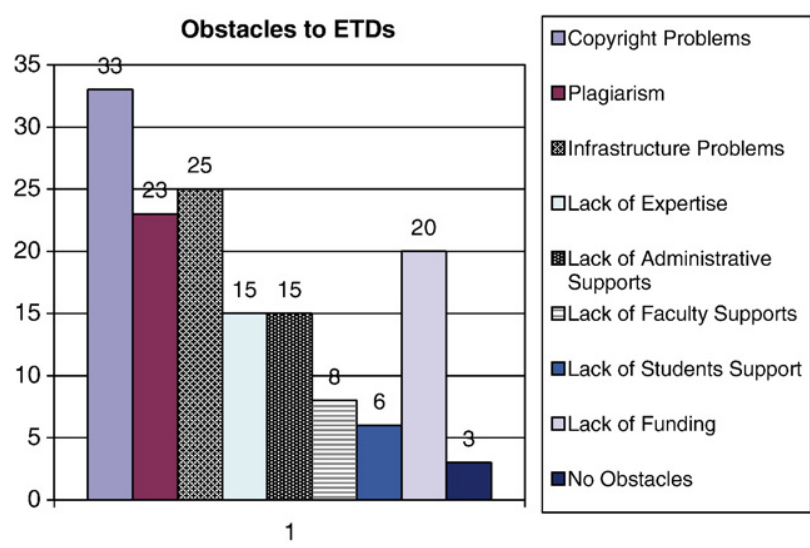

Smaller numbers, fifteen in each case (23 percent), identified lack of expertise or lack of administrative support as obstacles. Few respondents identified lack of support from students and faculty as a problem, and a very few declared that there are no obstacles in creating ETDs in their universities. These obstacles need to be resolved by government agencies such as the University Grants Commission, the Indian Council for Agriculture Research, the Indian Council for Medical Research, the All India Council for Technical Education, etc., specifically, by developing common policies and frameworks, providing sufficient financial support and promoting the benefits of ETDs among the academic and research community. Some of these obstacles may need to be addressed at institutional or regional level.

Table 1 shows that, except for four librarians, all respondents are well aware of the benefits of ETDs listed in the table, which are also widely agreed by ETD communities at international level. Even so, greater awareness about the benefits will definitely help in initiating this new idea in Indian universities.

\section{Attitudes Towards Hosting ETDS in Other Digital Archives}

Only twelve universities (18 percent) out of the sixty-five responding had adopted a policy to host their own ETDs in an external digital archive; the majority, that is forty-eight (74 percent), did not indicate a policy of doing so. ${ }^{1}$ (However, the majority of these did not collect theses in electronic format as yet and therefore would have no reason to have such a policy at this stage.) If we compare the statistics, only 15 percent of all sixty-five libraries supported access to ETDs outside their campus Intranet and only 18 percent have a policy to provide their ETDs to any national level agency, for the benefit of the wider academic and research community. These two are the important issues, which need to be resolved through national level policies and frameworks, and possibly mandatory requirements by governmental agencies.

Of the twelve universities who have a policy to host their ETDs in another digital archive, eleven indicated they were willing to provide their ETDs to a digital archive created by any UGC designated national agency and nine would select any university designated by UGC (see Fig. 2). ${ }^{2}$ Few are 


\begin{tabular}{|c|c|}
\hline $\begin{array}{r}\text { Table 1 } \\
\text { Benefits of ET } \\
\text { (Respondents Could Select More }\end{array}$ & Response) \\
\hline Benefits & Responses \\
\hline $\begin{array}{l}\text { Enhanced image in information } \\
\text { technology advancements }\end{array}$ & 30 \\
\hline Increased visibility of university research & 53 \\
\hline Avoiding duplication in research & 53 \\
\hline $\begin{array}{l}\text { Expertise in building digital } \\
\text { libraries/institutional repositories }\end{array}$ & 33 \\
\hline Promoting electronic publishing & 28 \\
\hline Libraries role in content development & 36 \\
\hline Not responded & 4 \\
\hline
\end{tabular}

either ready to provide their ETDs to private agencies or are not ready to provide to any one of the suggested bodies. This highlights the role to be played by the UGC in this area, with appropriate governance and regulations.

\section{The INFLIBNET Theses Database}

Of the sixty-five respondents, sixty-two (95 percent) stated that they are aware of the INFLIBNET Theses Database and three of them ( 5 percent) were not, indicating the popularity of this database among librarians. Forty-eight respondents (74 percent) indicated they regularly contribute thesis data to the INFLIBNET database, and seventeen (26 percent) are not contributing, although most of the participants are members of INFLIBNET and have a mandate to supply the data regularly. Steps must be taken by INFLIBNET to increase the coverage of its databases by including all universities under its umbrella.

\section{Future Plans for ETD Systems}

While it is very pleasing that eighteen ( 28 percent) of the Indian university libraries in this survey have already started the creation of ETD systems, it is a matter of concern that the majority, forty-seven (72 percent), had not started at the time of the survey. The unavailability of infrastructure and

\section{Figure 2}

Selection of a Digital Archive (Respondents Could Select More than One Response)

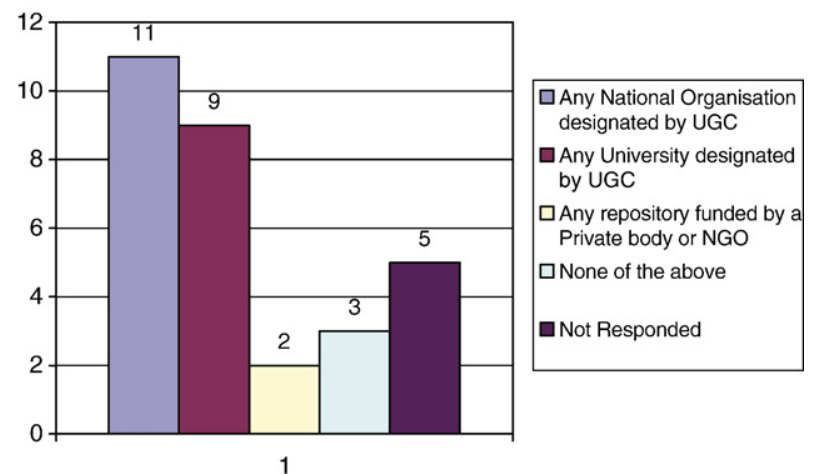

technical expertise would seem to be reasons for the gap, according to Fig. 1, and these problems may be resolved with the emergence and full operation of projects such UGC Infonet. ${ }^{3}$ The majority of the respondents without a current system, that is, thirty of the forty-seven (61 percent), were planning to create an ETD system in the year 2005 although the remaining nineteen (39 percent) did not have immediate plans to develop an ETD system. However, the awareness of the benefits of ETDs shown by university librarians in this survey, and the growing electronic culture in Indian university libraries will encourage further digital initiatives of this kind.

However, these developments cannot progress without support systems in place. Considerable need for support was expressed by respondents in relation to adequate policies from universities, and government bodies such as UGC, infrastructure, and technical expertise. Smaller numbers of respondents also required more support from academics or financial support. Twelve university librarians stated they did not require any kind of support, since their universities have sufficient infrastructure, funding and technical expertise, and are in the forefront of the digital revolution (Table 2).

\section{University Researchers-PhD Supervisors}

A separate survey was conducted with eighty-eight $\mathrm{PhD}$ research supervisors from various disciplines, covering twentyseven universities across the country. Of this group, fifty-three (60 percent) supervisors were aware of ETD initiatives, but thirty-four (39 percent) were not aware of the concept, indicating that an awareness program may required before initiating ETD programs in campuses. ${ }^{4}$ Faculty members in general were very supportive of an ETD program, with seventyfive (85 percent) supporting the concept, and only twelve (14 percent) not supporting the deposit of their student's PhD theses in electronic format at the time of submission. An even greater majority, seventy-eight ( 89 percent), support online access to theses, with only nine (10 percent) not supporting the concept. Academic resistance towards ETDs does not appear to be an issue in India.

Of the seventy-eight academics supporting online access, fifty (64 percent) expressed support for global access to their student's $\mathrm{PhD}$ theses over the Internet, while nineteen (24

Table 2

Support Needed for ETD System

(Respondents Could Select More than One Response; Three Respondents Did not Answer this Question)

\begin{tabular}{lc}
\hline \multicolumn{1}{c}{ Supports Needed } & Responses \\
\hline Governmental policies (UGC, etc.) & $28(43 \%)$ \\
University policies & $36(55 \%)$ \\
Infrastructure support & $32(49 \%)$ \\
Technical expertise & $27(41 \%)$ \\
Support from academics & $17(26 \%)$ \\
Financial supports & $19(29 \%)$ \\
No support required & $12(18 \%)$ \\
Not responded & $3(0.04 \%)$ \\
\hline
\end{tabular}


percent) were only willing to support access on a campus intranet and nine (12 percent) would support access only on a library LAN. Some of these more negative opinions may diminish along with the emergence of a digital information environment in Indian campuses when they are fully covered under the UGC Infonet program.

Reasons given by the nine academics who did not support online access focused on concerns about of the risk of plagiarism (seven responses), copyright issues (six responses), and lack of expertise in those managing and accessing the system (four responses). Lack of faculty support, lack of funding, and lack of administrative support are each identified by one respondent (one respondent did not reply to this question).

\section{Publication Practices of PhD Research}

The survey also asked respondents about the outlets in which they published their $\mathrm{PhD}$ research results. Of the eighty-eight academics in the survey, sixty-nine (78 percent) indicated that they had published their $\mathrm{PhD}$ results in journals, and sixty-five (74 percent) in conference proceedings, ten (11 percent) had published in book format, and three (3 percent) had not published any where. There were eleven respondents who did not reply to this question, and obviously some published their results in several formats. Clearly Indian $\mathrm{PhD}$ research is being published in other formats than the thesis itself, but the time gap between thesis completion and publication and between publication and the availability of those publications in libraries are an obstacle in disseminating Indian research outputs. Also, it is rare for any thesis to be published in its fullest form; thus, using traditional publishing formats, part of the thesis may not get published in any form.

\section{PhD Students}

In a third survey with a different questionnaire, $173 \mathrm{PhD}$ research students participated from various disciplines, covering twenty-seven universities across the country. Just over half of this group, ninety-six (56 percent) were aware of the concept of ETDs, with seventy-five (43 percent) indicating they were not aware. This is in contrast to the faculty responses and is likely because these researchers are in the initial stages of their research work and have not started using electronic information resources widely. However, of these $173 \mathrm{PhD}$ candidates, 148 (86 percent) were interested in providing an electronic copy of their thesis at the time of submission, with only a small minority of twenty-five (14 percent) unwilling to do so-a good sign that resistance to electronic thesis deposit is unlikely to be very strong in the emergent research community. Another very large majority, 144 ( 83 percent) of $\mathrm{PhD}$ students expressed willingness to provide online access to their $\mathrm{PhD}$ thesis through a digital library, with, again, a minority of twenty-six (15 percent) not willing to do so. ${ }^{5}$

Of the $144 \mathrm{PhD}$ students who support online access, ninetysix (66 percent) preferred global access through the Internet, twenty-seven (19 percent) preferred access on a library LAN, and twenty-one (15 percent) preferred access through a campus intranet. Thus, in total, 44 percent of $\mathrm{PhD}$ students are still not ready to provide global online access to their theses. They may be ready to provide online access after a time gap, after they have published articles, papers, or books based on their research. And if somebody wants to apply for a patent based on the research, especially in technology disciplines, the research must remain unpublished until that is granted.

Among the twenty-six who did not support online access, twenty-three (88 percent) identified copyright issues, nine (35 percent) identified the risk of plagiarism, six (23 percent) identified lack of administrative support, and five (20 percent) identified lack of expertise as the reasons to avoid online access to $\mathrm{PhD}$ theses. Three respondents stated they were not interested in providing wide availability to their theses.

The publication intentions of this group for their of $\mathrm{PhD}$ research strongly favored journal articles (131 respondents, or 76 percent), while seventy-eight (45 percent) had plans to publish in conference proceeding, and fifty-two (30 percent) had plans to publish a book from their thesis. Seven (4 percent) had no plans to publish their research work. Although the number in this group intending to publish their research as a book is greater than the number of faculty who have achieved this, it is clear that the dissemination of Indian academic research is primarily based on publications through articles and conferences, and that the publication of books based on $\mathrm{PhD}$ research is not common practice by faculty or student researchers.

\section{Summary}

In conclusion, it seems that the majority of supervisors, research students, and university librarians are well aware of ETD initiatives at the international level. Although very few universities had adopted a policy to collect electronic format of $\mathrm{PhD}$ theses along with print submission at the time of this study, a good majority of supervisors and research students are willing to provide their theses in electronic format to their university. Most supervisors and research students support the concept of online access to their ETDs, but only a moderate majority of university librarians support this idea. However, in relation to access policies, there is only a moderate majority of researchers who support global access to $\mathrm{PhD}$ theses through the Internet, a substantial minority preferring access over a library LAN or a campus intranet.

The majority of university librarians think copyright issues will be an obstacle in creating ETDs, along with the risk of plagiarism, lack of funding, and administrative support. Government policies are also seen as obstacles in creating ETDs in Indian campuses. Fewer research scholars identified these as obstacles in creating ETDs. A small number of universities have already started creating their ETD system, and majority of the rest had plans to have ETDs by the end of 2005. Of those that have moved towards establishing ETDs, very few have adopted a policy of hosting their ETDs in any other digital archive although the majority of them are willing to provide the content to any national level organization.

Indian university libraries are looking for policies from government agencies such as the UGC and infrastructure support, technical expertise, financial support from their own institutions to create ETD systems in their campuses. While the majority of the Indian academic community access the INFLIBNET Theses Database, effective awareness programs are required to increase its visibility, and its coverage, along with better coverage and awareness of the AIU University News and Handbook in order to increase the effectiveness of research. 
Finally, this study provides some further understanding about Indian $\mathrm{PhD}$ theses collections and stakeholders' attitudes towards electronic publishing of theses. Even though there are many issues yet to be resolved, the study clearly shows the trend towards the creation, organization, and dissemination of this form of research information in electronic format. In the near future, every Indian university is likely to collect electronic formats of $\mathrm{PhD}$ theses and host them in a digital archive, which will be accessible through a campus intranet or through the Internet, according to their access policies. While this idea is in the initial stages, it would be better to have a common policy accepted by all universities, in terms of format, workflow, software, accessing, and archiving policies, which will help them to share this valuable resource through a national level platform identified by governmental agencies working in this area, such as INFLIBNET.

\section{NOTES AND REFERENCES}

1. Five respondents did not answer this question.

2. Five of the universities which had EDTs did not respond to this question.

3. Managed by INFLIBNET, Infonet is an ambitious program of the UGC to build up its own nation wide high speed communication network of academic institutions. Access to subscribed E-journals, E-books, and databases is the main feature, while a national data centre, which can act as a repository for contents like ETDs, will be a part of this project.

4. There was one respondent who did not reply to this, and the two following questions.

5. Three respondents did not reply to this question. 